\title{
Respiratory Effects of Adaptive Servoventilation Therapy in Patients with Heart Failure and Cheyne-Stokes Respiration Compared to Healthy Volunteers
}

\author{
Jens Spießhöfer Jessica Heinrich Roman Lehmann Christina Efken \\ Henrik Fox Thomas Bitter Britta Körber Dieter Horstkotte Olaf Oldenburg \\ Department of Cardiology, Heart and Diabetes Centre North Rhine-Westphalia, Ruhr University Bochum, \\ Bad Oeynhausen, Germany
}

\section{Key Words}

Sleep-disordered breathing - Cheyne-Stokes respiration . Adaptive servoventilation · Heart failure - Carbon dioxide . Respiratory control

\begin{abstract}
Background: Nocturnal adaptive servoventilation (ASV) therapy is now frequently used to treat Cheyne-Stokes respiration (CSR), which is highly prevalent in patients with moderate-to-severe heart failure (HF) and characterized by periodical breathing (hyperventilation). Objectives: This study analyzed and compared the acute effects of a novel ASV device on carbon dioxide pressure $\left(\mathrm{pCO}_{2}\right)$ and oxygen saturation $\left(\mathrm{SaO}_{2}\right)$ in $\mathrm{HF}$ patients with $\mathrm{CSR}$ and healthy volunteers. The influence of being asleep or awake on the ASV algorithm was also determined. Methods: All subjects underwent ASV (PaceWave ${ }^{\mathrm{TM}}$, ResMed) for $1 \mathrm{~h}$. Transcutaneous $\mathrm{pCO}_{2}\left(\mathrm{PtcCO}_{2}\right)$ and $\mathrm{SaO}_{2}$ were assessed transcutaneously, while wakefulness was analyzed using EEG recordings. Assessments were made 30 min before and after ASV, and during $1 \mathrm{~h}$ of ASV. Results: Twenty HF patients (19 male; age 79 \pm 12 years) and 15 volunteers (13 male, age $25 \pm 4$ years) were included. When awake, ASV was associated with a trend towards a decrease in $\mathrm{PtcCO}_{2}$ and an increase in $\mathrm{SaO}_{2}$
\end{abstract}

versus baseline in HF patients ( $34.4 \pm 3.2$ to $33.7 \pm 3.8 \mathrm{~mm} \mathrm{Hg}$ and $93.8 \pm 2.6$ to $94.9 \pm 2.6 \%$, respectively) and volunteers ( $39.5 \pm 3.0$ to $38.2 \pm 3.8 \mathrm{~mm} \mathrm{Hg}$ and $96.9 \pm 1.3$ to $97.8 \pm 0.9 \%$ ). While asleep during ASV, $\mathrm{PtcCO}_{2}$ increased to $36.3 \pm 3.8 \mathrm{~mm}$ $\mathrm{Hg}$ and $\mathrm{SaO}_{2}$ decreased to $93.8 \pm 2.6 \%$ in $\mathrm{HF}$ patients, with similar changes in volunteers $\left(\mathrm{PtcCO}_{2} 41.7 \pm 3.0 \mathrm{~mm} \mathrm{Hg}\right.$, $\mathrm{SaO}_{2} 97.1 \pm 1.2$ ). All comparisons were statistically significant ( $\mathrm{p} \leq 0.05$, except the $\mathrm{PtcCO}_{2}$ decrease in both groups when awake). Conclusions: ASV therapy might result in hyperventilation when subjects are awake, but while asleep, $\mathrm{PtcCO}_{2}$ increased to mid-normal values, effects that would be favorable in HF patients with CSR.

(c) 2015 S. Karger AG, Basel

\section{Introduction}

Sleep-disordered breathing is a highly prevalent comorbidity in heart failure (HF) patients [1]. Whereas obstructive sleep apnea seems to be a risk factor for the development of HF [2], central sleep apnea (CSA) with a Cheyne-Stokes respiration (CSR) pattern seems to mirror cardiac function in these patients [3]. Therefore, CSR is seen more often when HF is advanced [3].

\section{KARGER 125}

C 2015 S. Karger AG, Basel

$0025-7931 / 15 / 0895-0374 \$ 39.50 / 0$

E-Mail karger@karger.com

www.karger.com/res
Olaf Oldenburg, MD

Department of Cardiology, Heart and Diabetes Centre North Rhine-Westphalia University Hospital, Ruhr University Bochum

Georgstrasse 11, DE-32545 Bad Oeynhausen (Germany)

E-Mail akleemeyer@hdz-nrw.de 
Although the pathophysiology of CSR in HF is still not fully understood, pulmonary congestion due to left ventricular dysfunction with increased pulmonary capillary wedge pressure is thought to lead to an activation of pulmonary J receptors. This could promote a greater sensitivity of central $\mathrm{CO}_{2}$ chemoreceptors and, consequently, an altered apneic threshold with the net effect of an increase in ventilation (hyperventilation) with low-normal to decreased levels of $\mathrm{CO}_{2}$ [3].

During sleep and in patients with CSA (in contrast to healthy men), the above-mentioned higher sensitivity towards carbon dioxide pressure $\left(\mathrm{pCO}_{2}\right)$ explains why they periodically reach the apneic threshold, resulting in repetitive apneas [4]. Thus, in patients with CSR, one or two deep breaths can be enough to cause an apnea [4].

There is currently no clear consensus on whether CSR in HF patients should be treated because opinion varies as to whether CSR just represents a compensatory physiological mechanism of the failing heart or whether it might be an independent risk factor for death $[5,6]$. Therefore, the results of large multicenter, randomized clinical studies investigating the impact of adaptive servoventilation (ASV) therapy on mortality in such patients are awaited with interest [7].

Nevertheless, the most effective method for treating CSR in HF is ASV or, more recently, enhanced ASV (eASV) [8-11]. ASV has been shown to be more effective than continuous positive airway pressure (CPAP), bilevel positive airway pressure (BiPAP) therapy or oxygen therapy and to improve cardiac function $[8-10,12]$. With ASV, upper airway patency is ensured by a fixed amount of end-expiratory positive airway pressure (EPAP) or a varied amount of EPAP (known as eASV; accounting for comorbid obstructive events in HF patients with CSR), while a varying amount of inspiratory pressure (inspiratory positive airway pressure, IPAP) supports inspiration with decreasing breathing amplitude or even ensures inspiration with sustained breathing efforts [9]. All available ASV devices indirectly aim to avoid hyperventilation by dynamically decreasing effective minute ventilation to $90 \%$ of the patient's ventilation analyzed over a period of the last $3 \mathrm{~min}$. Thus, the net effect is supposed to be a (desired) increase in $\mathrm{pCO}_{2}$ during the night, which is another feature differentiating ASV from oxygen, CPAP or BiPAP therapies. The ASV device used in this study was one of the latest (enhanced) ASV devices now available, the third-generation PaceWave ${ }^{\mathrm{TM}}$ device (ResMed).

To the best of our knowledge, it has not yet been shown whether eASV is associated with the desired in- crease in $\mathrm{pCO}_{2}$ in HF patients with CSR. Therefore, this study investigated the effects of $60 \mathrm{~min}$ of ASV treatment on oxygen saturation $\left(\mathrm{SaO}_{2}\right)$ and $\mathrm{pCO}_{2}$ in $\mathrm{HF}$ patients with CSR and in healthy volunteers. In addition, we analyzed the influence of sleep on ASV (falling asleep was only allowed during ASV therapy). This observation was intended to verify whether the abovementioned ASV algorithm of a $90 \%$ flow-triggered target minute volume can only be administered sufficiently during sleep. It was hypothesized that this (mechanical) control of breathing might only be successful in sleeping patients/volunteers.

\section{Material and Methods}

\section{Study Design}

A cohort of healthy medical student volunteers and HF patients with CSR were ventilated for $1 \mathrm{~h}$. The effects of ventilation were determined by comparing assessments made 30 min before and after ventilation and without any mask or intervention in place (fig. 1). Both patients and volunteers were asked to stay awake during the $30 \mathrm{~min}$ before and after ASV but were asked to fall asleep - if possible - while receiving ASV. The effects of ASV on transcutaneous $\mathrm{pCO}_{2}\left(\mathrm{PtcCO}_{2}\right)$ and $\mathrm{SaO}_{2}$ were first analyzed in all participants, irrespective of any sleeping during ASV, and then in those who actually slept during ASV.

\section{Methods}

From July 2012 to January 2013, 20 consecutive patients with stable HF [left ventricular ejection fraction (LVEF) $<50 \%$; New York Heart Association class $\geq \mathrm{II}$ ] and nocturnal CSR [apnea-hypopnea index $(\mathrm{AHI}) \geq 15 / \mathrm{h}$ ] who were receiving treatment with ASV and 15 healthy, young medical students (LVEF $\geq 60 \%$, AHI $<5 /$ h, no history of disease) were enrolled. Echocardiography was performed in all participants to determine LVEF and other cardiac parameters. Additional clinical data (hypercapnic ventilatory response, diffusion capacity and pulmonary function) were obtained from patients before initiation of their ongoing nocturnal ASV treatment.

The study protocol was approved by the local ethics committee, and all patients and volunteers gave written informed consent to participate in the trial. The study was carried out in accordance with the Declaration of Helsinki.

After resting in a supine position for at least $20 \mathrm{~min}, \mathrm{SaO}_{2}$, $\mathrm{PtcCO}_{2}$ and wakefulness were continuously monitored for another 30 min before, during $1 \mathrm{~h}$ of ASV and 30 min after ASV [Pace$\mathrm{Wave}^{\mathrm{TM}}$ device (ResMed), third-generation (enhanced) ASV device] using polysomnography (PSG; SOMNOscreen ${ }^{\mathrm{TM}}$ plus, Somnomedics $-\mathrm{SaO}_{2}$ and vigilance) and transcutaneous measurement $\left(\mathrm{V}\right.$-Stats ${ }^{\mathrm{TM}}$ 3.00, SenTec AG - $\mathrm{pCO}_{2}$ ). PSG consisted of a 12-channel EEG and a finger sensor measuring $\mathrm{SaO}_{2}$ four times each second. $\mathrm{PtcCO}_{2}$ measurements were taken every $4 \mathrm{~s}$. All investigations were performed in a quiet room, allowing the patients and volunteers to fall asleep during ASV (but not in the $30 \mathrm{~min}$ before and after ASV). 


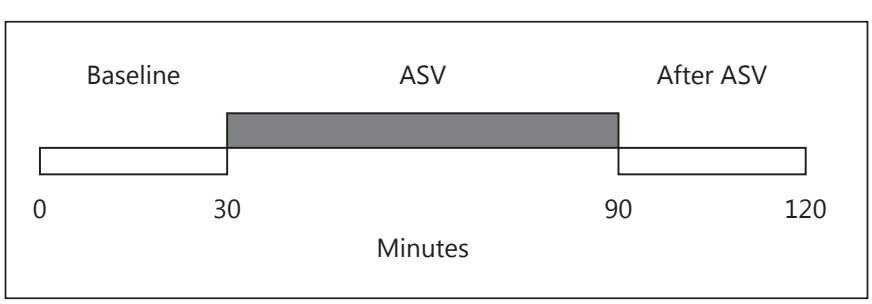

Fig. 1. Study protocol. All subjects were awake in the $30 \mathrm{~min}$ before and after ASV but were free to fall asleep during ASV.

With regard to the analysis of $\mathrm{pCO}_{2}$ levels during sleep, the focus was on identifying periods where sleep was continuous. Therefore, shorter periods of sleep $(<3 \mathrm{~min})$ or shorter transitions to sleep were disregarded so that $\mathrm{pCO}_{2}$ levels could be averaged for stable periods where subjects were definitely asleep or awake.

The following strategy for ASV pressure settings was applied to ensure that both subject groups were exposed to comparable pressure levels: HF patients were ventilated using their median therapeutic pressure levels as a minimum for EPAP and IPAP for this $1 \mathrm{~h}$ of ASV (median therapeutic pressure values were taken from a hard copy printout of data from the ASV device they were already being treated with). The volunteers were enrolled into the study after the patients, and the mean values of the median EPAP and IPAP values used in HF patients were used as a minimum.

The DOMINO software (version 2.5.0, Somnomedics) was used to analyze sleep stages, which was performed in accordance with the most recent guidelines of the American Association of Sleep Medicine (AASM) [13]. The AASM guidelines were also applied when analyzing the polygraphic examinations of patients and volunteers that were undertaken to verify sleep-disordered breathing. Both the DOMINO software and the $\mathrm{V}$-Stats ${ }^{\mathrm{TM}} 3.00$ software were used to compare mean values of $\mathrm{SaO}_{2}$ and $\mathrm{PtcCO}_{2}$ for the 30 min before, $1 \mathrm{~h}$ during and $30 \mathrm{~min}$ after ASV (part one of the analysis - overall effects regardless of vigilance during ASV). Subsequently, both $\mathrm{PtcCO}_{2}$ and $\mathrm{SaO}_{2}$ during ASV were analyzed depending on wakefulness in patients and volunteers who fell asleep during ASV (part two of the analysis; 'awake during ASV' vs. 'asleep during ASV').

\section{Statistical Analysis}

All analyses were performed using Sigma Plot software (version 11.0, Systat Software Ltd.). Results are expressed as mean \pm standard deviation. A one-way repeated measures ANOVA was employed to detect statistically significant overall intraindividual differences in $\mathrm{PtcCO}_{2}$ and $\mathrm{SaO}_{2}$.

A paired t test was used to directly compare differences in Ptc$\mathrm{CO}_{2}$ and $\mathrm{SaO}_{2}$ in the corresponding periods, whereas a t test was employed if different groups of patients or volunteers were compared. The Mann-Whitney rank sum test was used when data did not have a normal distribution. A $\chi^{2}$ test was used for categorical data. Pearson correlation was employed to correlate the percentage of time spent sleeping during ASV with changes in $\mathrm{PtcCO}_{2}$. A p value $<0.05$ was considered to be statistically significant.

\section{Results}

A total of 20 patients and 15 healthy volunteers were enrolled. Detailed demographic and clinical data are summarized in table 1.

\section{ASV Settings and Pressure Exposure}

ASV settings for HF patients were chosen according to their previous settings, shown to effectively suppress CSR in a chronic setting. An EPAP of $7.3 \pm 2.0 \mathrm{~cm} \mathrm{H}_{2} \mathrm{O}$, a pressure support (PS) of $4.2 \pm 1.1 \mathrm{~cm} \mathrm{H}_{2} \mathrm{O}$ and a resulting IPAP of $11.5 \pm 2.2 \mathrm{~cm} \mathrm{H}_{2} \mathrm{O}$ were set as a minimum and corresponded to each patient's median pressure level for chronic treatment. Using these settings was associated with the following median values during the 1-hour ASV treatment period in the cohort of patients: EPAP $8.3 \pm 1.8$ $\mathrm{cm} \mathrm{H}_{2} \mathrm{O}$, PS $6.2 \pm 1.4 \mathrm{~cm} \mathrm{H}_{2} \mathrm{O}$, IPAP $14.5 \pm 2.4 \mathrm{~cm} \mathrm{H}_{2} \mathrm{O}$. To ensure a comparable pressure exposure for healthy volunteers, the following settings were used as a minimum: EPAP $8 \pm 0 \mathrm{~cm} \mathrm{H}_{2} \mathrm{O}$, PS $6.0 \pm 0 \mathrm{~cm} \mathrm{H}_{2} \mathrm{O}$ and IPAP $14 \pm 0 \mathrm{~cm} \mathrm{H}_{2} \mathrm{O}$ (table 1).

\section{Overall Effect of ASV on $\mathrm{PtcCO}_{2}$ and $\mathrm{SaO}_{2}$ (Regardless} of Sleep during ASV)

As expected, baseline values for $\mathrm{PtcCO}_{2}$ and $\mathrm{SaO}_{2}$ were different in HF patients with documented CSA compared with healthy volunteers. PtcCO $\mathrm{CO}_{2}$ was $34.0 \pm 2.9 \mathrm{~mm} \mathrm{Hg}$ in HF patients versus $39.3 \pm 2.6 \mathrm{~mm} \mathrm{Hg}$ in volunteers $(\mathrm{p}<$ 0.001 ), and $\mathrm{SaO}_{2}$ values were $94.2 \pm 2.4$ and $97.1 \pm 1.2 \%$, respectively $(\mathrm{p}<0.001)$. These differences between groups were maintained throughout the study, although relative changes during treatment were in the same direction in both subject groups. Overall, patients tended to have a lower $\mathrm{PtcCO}_{2}$ than volunteers (fig. 2).

Overall, without taking into account wakefulness, ASV had no significant effects on $\mathrm{PtcCO}_{2}$ and $\mathrm{SaO}_{2}$. In healthy volunteers, $\mathrm{PtcCO}_{2}$ was $39.3 \pm 2.6 \mathrm{~mm} \mathrm{Hg}$ before ASV, $37.2 \pm 5.2 \mathrm{~mm} \mathrm{Hg}$ during ASV and $39.1 \pm 2.7 \mathrm{~mm}$ $\mathrm{Hg}$ after ASV. However, $\mathrm{SaO}_{2}$ improved significantly from $97.1 \pm 1.2 \%$ before ASV to $97.7 \pm 1.0 \%$ during ASV $(\mathrm{p}=0.004)$. In patients with $\mathrm{HF}, \mathrm{PtcCO}_{2}$ also remained stable $(34.0 \pm 2.9 \mathrm{~mm} \mathrm{Hg}$ before ASV, $33.6 \pm 4.3 \mathrm{~mm} \mathrm{Hg}$ during ASV and $34.1 \pm 3.5 \mathrm{~mm} \mathrm{Hg}$ after ASV), while $\mathrm{SaO}_{2}$ improved from $94.2 \pm 2.4 \%$ before ASV to $94.9 \pm 2.5 \%$ during ASV ( $\mathrm{p}=0.008)$.

\section{Effects of $\mathrm{ASV}$ on $\mathrm{PtcCO}_{2}$ and $\mathrm{SaO}_{2}$ in Dependence of Sleep during ASV}

Fifteen of the 20 patients and 11 of the 15 volunteers fell asleep during ASV, with a mean sleep time of $29.4 \pm$ 
Table 1. Demographic and clinical characteristics of patients and volunteers

\begin{tabular}{|c|c|c|}
\hline & HF patients $(\mathrm{n}=20)$ & Volunteers $(\mathrm{n}=15)$ \\
\hline \multicolumn{3}{|l|}{ Clinical characteristics } \\
\hline Age, years & $68.7 \pm 11.7$ & $24.9 \pm 3.8$ \\
\hline Male, \% & 96.7 & 86.7 \\
\hline LVEF, \% & $36.0 \pm 7.8$ & $\geq 65$ \\
\hline Systolic blood pressure, $\mathrm{mm} \mathrm{Hg}$ & $110.8 \pm 14.3$ & $127.6 \pm 11.9$ \\
\hline Diastolic blood pressure, $\mathrm{mm} \mathrm{Hg}$ & $67.8 \pm 11.2$ & $76.3 \pm 8.5$ \\
\hline NYHA class & $2.4 \pm 0.5$ & 0 \\
\hline Body mass index & $29.3 \pm 5.2$ & $23.0 \pm 2.5$ \\
\hline Sinus rhythm, \% & 60 & 100 \\
\hline Atrial fibrillation, \% & 40 & 0 \\
\hline Pacemaker, \% & 30 & 0 \\
\hline Coronary artery disease, $\%$ & 55 & 0 \\
\hline Diabetes, \% & 45 & 0 \\
\hline \multicolumn{3}{|l|}{ Medication } \\
\hline$\beta$-Blockers, $\%$ & 95 & 0 \\
\hline ACEI/ARB, \% & 100 & 0 \\
\hline Aldosterone antagonists, \% & 10 & 0 \\
\hline Diuretics, \% & 70 & 0 \\
\hline Digitalis glycosides, \% & 10 & 0 \\
\hline Calcium channel blocker, $\%$ & 10 & 0 \\
\hline Amiodarone, $\%$ & 5 & 0 \\
\hline \multicolumn{3}{|l|}{ Sleep laboratory parameters } \\
\hline Minimum PS $\left(\mathrm{cm} \mathrm{H}_{2} \mathrm{O}\right)$ & $4.2 \pm 1.1$ & $6.0 \pm 0.0$ \\
\hline Minimum EPAP $\left(\mathrm{cm} \mathrm{H}_{2} \mathrm{O}\right)$ & $7.3 \pm 2.0$ & $8.0 \pm 0.0$ \\
\hline Median leakage $\pm \mathrm{SD}, 1 / \mathrm{min}$ & $2.3 \pm 5.6$ & $0.2 \pm 0.6$ \\
\hline 95th percentile $\pm \mathrm{SD}$ & $5.3 \pm 8.3$ & $0.8 \pm 2.2$ \\
\hline Maximum \pm SD & $14.1 \pm 20.3$ & $1.3 \pm 2.3$ \\
\hline Median breathing frequency $\pm \mathrm{SD}$, /min & $13.1 \pm 2.9$ & $9.7 \pm 2.9$ \\
\hline 95th percentile $\pm \mathrm{SD}$ & $15.8 \pm 3.5$ & $12.8 \pm 4.4$ \\
\hline Maximum \pm SD & $17.5 \pm 3.9$ & $15.2 \pm 5.6$ \\
\hline Median breathing volume $\pm \mathrm{SD}, \mathrm{ml} /$ breath & $554.6 \pm 140.6$ & $668.0 \pm 344.7$ \\
\hline 95th percentile \pm SD & $712.4 \pm 261.2$ & $981.3 \pm 583.5$ \\
\hline Maximum \pm SD & $900.4 \pm 408.4$ & $1,096.0 \pm 647.1$ \\
\hline Breathing minute volume $\pm \mathrm{SD}, 1$ & $7.2 \pm 1.7$ & $6.3 \pm 1.6$ \\
\hline 95th percentile \pm SD & $9.2 \pm 2.5$ & $7.8 \pm 2.2$ \\
\hline Maximum \pm SD & $10.7 \pm 3.2$ & $9.2 \pm 2.3$ \\
\hline Median $\mathrm{EPAP} \pm \mathrm{SD}, \mathrm{cm} \mathrm{H}_{2} \mathrm{O}$ & $8.3 \pm 1.8$ & $8.9 \pm 0.5$ \\
\hline 95th percentile $\pm \mathrm{SD}$ & $9.5 \pm 1.8$ & $9.2 \pm 0.8$ \\
\hline Maximum \pm SD & $9.7 \pm 1.9$ & $9.3 \pm 0.9$ \\
\hline Median PS, $\mathrm{cm} \mathrm{H}_{2} \mathrm{O}$ & $6.2 \pm 1.4$ & $8.2 \pm 1.6$ \\
\hline Median IPAP $\pm \mathrm{SD}, \mathrm{cm} \mathrm{H}_{2} \mathrm{O}$ & $14.5 \pm 2.4$ & $17.1 \pm 1.5$ \\
\hline 95th percentile $\pm \mathrm{SD}$ & $17.7 \pm 2.8$ & $20.1 \pm 2.2$ \\
\hline Maximum \pm SD & $19.9 \pm 2.5$ & $21.5 \pm 2.3$ \\
\hline Median target minute ventilation, 1 & $6.0 \pm 1.3$ & $5.6 \pm 1.4$ \\
\hline Residual AHI on ASV, /h & $1.6 \pm 3.8$ & $0.4 \pm 0.95$ \\
\hline AHI before treatment, $/ \mathrm{h}$ & $36.4 \pm 14.5$ & $1.9 \pm 1.5$ \\
\hline Apnea index, /h & $18.5 \pm 15.0$ & $0.3 \pm 0.5$ \\
\hline Central/obstructive, /h & $15.2 \pm 14.1 / 2.6 \pm 2.5$ & $0.2 \pm 0.3 / 0.1 \pm 0.3$ \\
\hline Hypopnea index, /h & $17.9 \pm 13.5$ & $1.6 \pm 1.6$ \\
\hline Duration of ASV therapy, months & $13.3 \pm 12.5$ & - \\
\hline \multicolumn{3}{|l|}{ ASV equipment, $\%$} \\
\hline AutoSet ${ }^{\mathrm{TM}}$ CS2 (ResMed) & 90 & - \\
\hline Somnovent ${ }^{\mathrm{TM}} \mathrm{CR}$ (Weinmann) & 10 & - \\
\hline
\end{tabular}


Table 1 (continued)

HF patients $(\mathrm{n}=20)$

Volunteers $(\mathrm{n}=15)$

Characteristics before chronic ASV treatment

6MWD, m

$316.5 \pm 146.9$

$2.9 \pm 1.0$

等,

$86.6 \pm 17.2$

FEV/IV

$100.2 \pm 12.5$

TLCO, \% normal

$72.9 \pm 9.8$

Values are expressed as mean \pm standard deviation unless otherwise stated. $6 \mathrm{MWD}=6$-min walk distance; $\mathrm{ACEI}=$ angiotensin-converting enzyme inhibitors; $\mathrm{ARB}=$ angiotensin receptor blockers; $\mathrm{FEV}_{1}=$ forced expiratory volume in $1 \mathrm{~s} ; \mathrm{HCVR}=$ hypercapnic ventilatory response; IVC = inspiratory vital capacity; $\mathrm{SD}=$ standard deviation; TLCO = diffusing capacity or transfer factor of the lung for carbon monoxide.
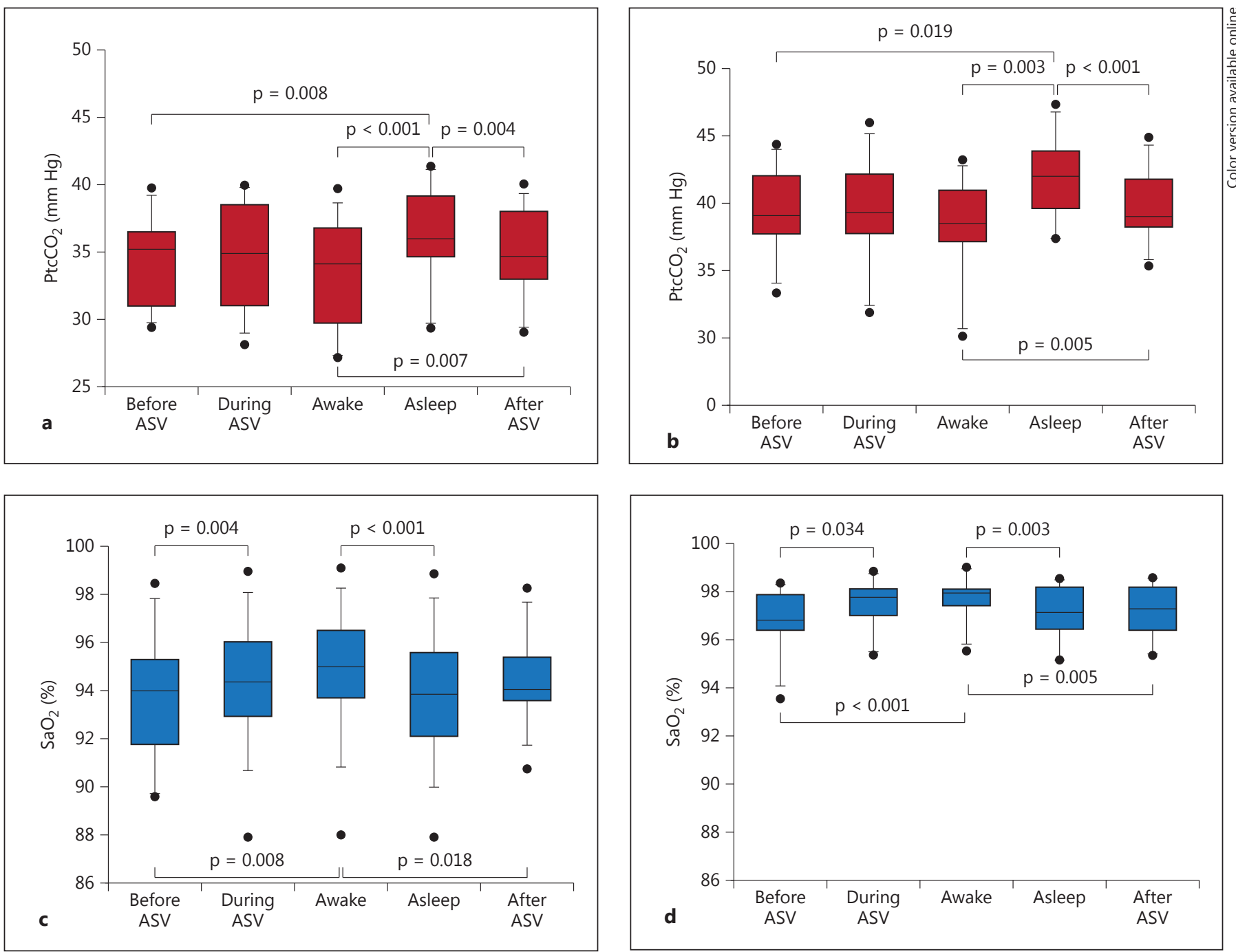

Fig. 2. Sleep-dependent changes in $\mathrm{PtcCO}_{2}$ and $\mathrm{SaO}_{2}$ in patients $(\mathrm{n}=15 ; \mathbf{a}, \mathbf{c})$ and volunteers $(\mathrm{n}=11 ; \mathbf{b}, \mathbf{d})$ undergoing $1 \mathrm{~h}$ of ASV. A one-way repeated measures ANOVA showed statistically significant overall differences in all four datasets $($ each $\mathrm{p}<0.001)$. 

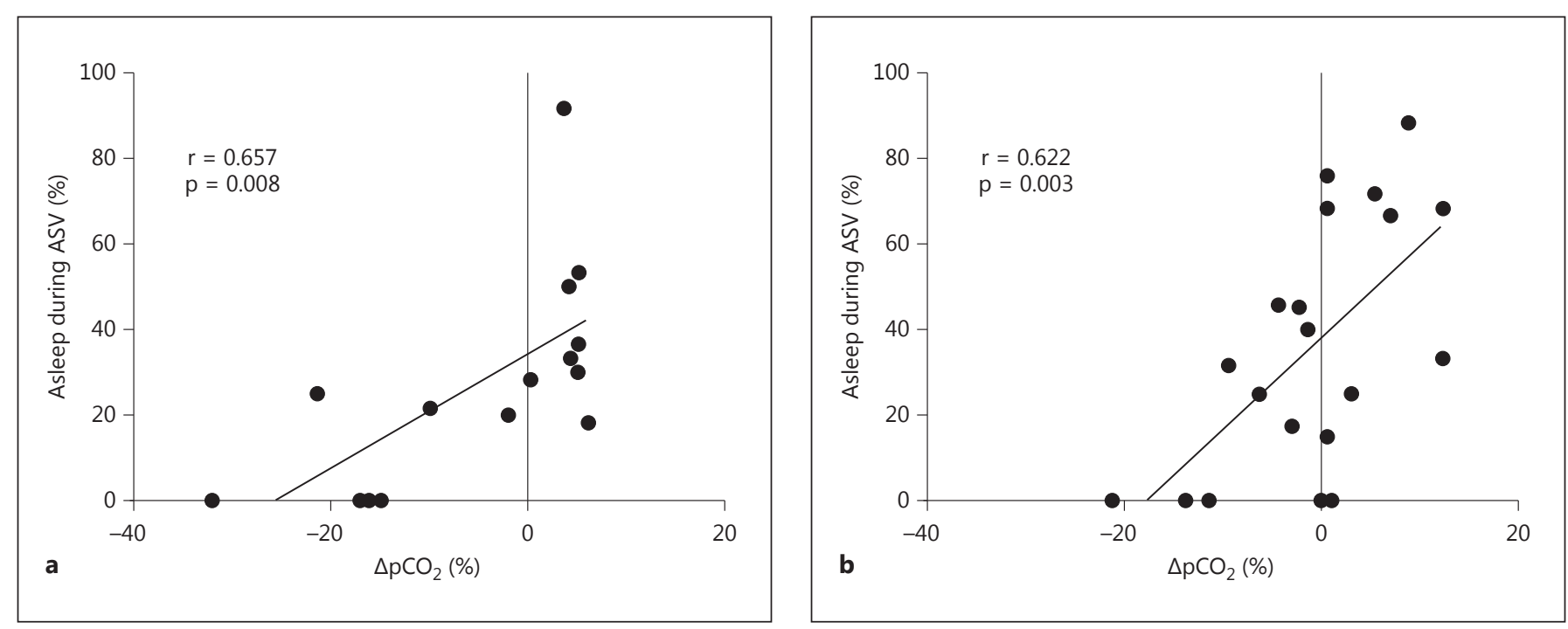

Fig. 3. Correlation of percent time slept during ASV with change in $\mathrm{PtcCO}_{2}$ (mean of 60 min during vs. 30 min before ASV) for volunteers (a) and patients (b).

$14.2 \mathrm{~min}(47.9 \pm 23.6 \%$ of total ASV time $)$ in patients and $22.3 \pm 12.9 \mathrm{~min}(37.1 \pm 21.4 \%$ of total ASV time $)$ in volunteers. No patients or volunteers exceeded sleep stage $\mathrm{N} 2$, which is why stages $\mathrm{N} 1$ and $\mathrm{N} 2$ were summarized as 'asleep'. In addition, none of the participants had any sleep segment with a duration of 3 min or less, so no segments of sleep had to be disregarded. Analysis of sleep stages was performed carefully so that stage N1 was definitely scored as such. Results of a subgroup analysis of the effects of ASV on $\mathrm{PtcCO}_{2}$ and $\mathrm{SaO}_{2}$ in HF patients and healthy volunteers, while awake and asleep are summarized in figures 2 and 3.

It is an important observation that the different effects of ASV therapy in HF patients and healthy volunteers are dependent on wakefulness. As indicated by a decrease in $\mathrm{PtcCO}_{2}$ and an increase in $\mathrm{SaO}_{2}$ in both subject groups when awake, ASV was associated with a trend towards a (further) increase in ventilation (hyperventilation). In contrast, while asleep during ASV treatment, $\mathrm{PtcCO}_{2}$ increased and $\mathrm{SaO}_{2}$ decreased in both subject groups. During ASV in $\mathrm{HF}$ patients, $\mathrm{PtcCO}_{2}$ was $33.7 \pm 3.8 \mathrm{~mm} \mathrm{Hg}$ while awake versus $36.3 \pm 3.8 \mathrm{~mm} \mathrm{Hg}$ while asleep $(\mathrm{p}<$ $0.001)$; the corresponding values for $\mathrm{SaO}_{2}$ were $94.9 \pm 2.6$ and $93.8 \pm 2.6 \%$, respectively $(\mathrm{p}<0.001)$.

The findings were similar in healthy volunteers, with a $\mathrm{PtcCO}_{2}$ of $38.2 \pm 3.8 \mathrm{~mm} \mathrm{Hg}$ while awake during ASV and $41.7 \pm 3.0 \mathrm{~mm} \mathrm{Hg}$ while asleep $(\mathrm{p}<0.001)$, and $\mathrm{SaO}_{2}$ values of $97.8 \pm 0.9$ and $97.1 \pm 1.2 \%$, respectively $(\mathrm{p}=$ 0.003 ). As can also be seen in figure 2 , the difference in
$\mathrm{PtcCO}_{2}$ also reached statistical significance in both subject groups for the comparison of asleep during ASV and before ASV. However, there were still marked interindividual variations in the change in $\mathrm{PtcCO}_{2}$ associated with ASV while asleep or awake. These variations were best explained taking into account the precise time slept during ASV in both subject groups.

There was a significant correlation between the percentage of time spent asleep during ASV and changes in $\mathrm{PtcCO}_{2}$ in both patients $(\mathrm{r}=0.622 ; \mathrm{p}=0.003)$ and volunteers $(\mathrm{r}=0.657 ; \mathrm{p}=0.008$; fig. 3$)$.

To further investigate factors associated with hyperventilation during ASV therapy, volunteers were divided into two groups based on the overall change from baseline in $\mathrm{PtcCO}_{2}$ during ASV. This was intended to extend previous findings by determining whether it was really only being asleep during ASV that accounted for the observed effects on $\mathrm{PtcCO}_{2}$. Five volunteers met the definition of hypocapnia $\left(\mathrm{PtcCO}_{2} \leq 35 \mathrm{~mm} \mathrm{Hg}\right)$ during ASV, and respiratory and sleep stage data of these subjects were compared with those of the remaining 10 volunteers (Ptc$\mathrm{CO}_{2}>35 \mathrm{~mm} \mathrm{Hg}$ ). A slightly different strategy was used for patients because underlying CSR meant that some were already hypocapnic before ASV. Therefore, 5 patients whose difference between mean $\mathrm{PtcCO}_{2}$ before and during ASV was $\geq 2 \mathrm{~mm} \mathrm{Hg}$ were identified (table 2). Hyperventilation in these patients was clearly evident based on respiratory parameters (i.e. breathing frequency, breathing volume and resulting breathing minute vol- 
Table 2. Respiratory parameters and sleep status of patients and volunteers based on $\mathrm{PtcCO}_{2}$ response during ASV

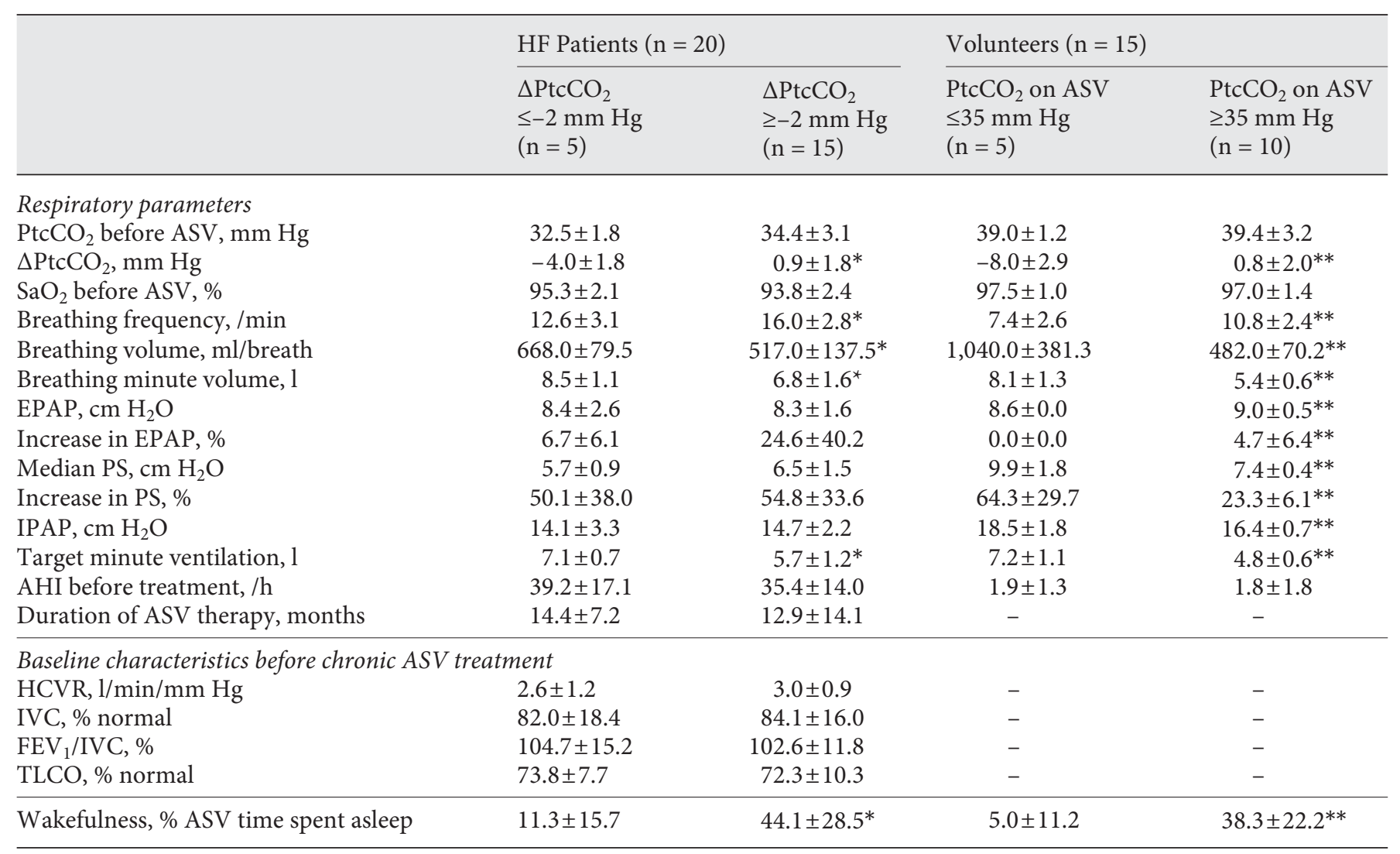

Values are expressed as mean \pm standard deviation unless otherwise stated. ${ }^{*} \mathrm{p} \leq 0.01$ vs. patients with $\Delta \mathrm{PtcCO}{ }_{2} \leq-2 \mathrm{~mm} \mathrm{Hg}^{* *} \mathrm{p} \leq$ 0.01 vs. volunteers with $\mathrm{PtcCO}_{2}$ on $\mathrm{ASV} \leq 35 \mathrm{~mm} \mathrm{Hg}$.

ume, and target minute ventilation) that were all statistically significantly higher than in the other 15 patients (difference in $\mathrm{PtcCO}_{2}$ before and during ASV $<2 \mathrm{~mm}$ $\mathrm{Hg}$ ). This deterioration of hyperventilation in 5 patients was not explained by baseline $\mathrm{PtcCO}_{2}, \mathrm{SaO}_{2}$ or any baseline patient characteristics, including PS or EPAP. However, patients with hyperventilation during ASV slept significantly less during ASV than those who did not (11.3 \pm 15.7 vs. $44.1 \pm 28.5 \%$ sleep time during ASV; $\mathrm{p}=0.026$ ).

A similar relationship was documented in healthy volunteers. The 5 volunteers with $\mathrm{PtcCO}_{2} \leq 35 \mathrm{~mm} \mathrm{Hg}$ slept significantly less during ASV compared with those without hyperventilation $(5.0 \pm 11.2$ vs. $38.3 \pm 22.2 \%$ sleep time during ASV; $p=0.008$ ). In healthy volunteers, another parameter was also significantly different in those with versus those without hyperventilation: the increase in PS was statistically significantly and clinically relevantly higher (64.3 \pm 29.7 vs. $23.3 \pm 6.1 \%$; $p=0.012$ ). This resulted in a statistically significantly higher IPAP in hyperventilated (quite awake) volunteers than in nonhyperventilated (quite asleep) volunteers $(18.5 \pm 1.8$ vs. $16.4 \pm 0.7 \mathrm{~mm} \mathrm{Hg}$; $=$ 0.031 ). Thus, in volunteers, both wakefulness and PS might be directly or indirectly responsible for hyperventilation.

\section{Discussion}

CSR itself is characterized by hyperventilation with low-normal to depressed $\mathrm{pCO}_{2}$, even during daytime while awake [3]. Indeed, in our study, $\mathrm{pCO}_{2}$ in $\mathrm{HF}$ patients with CSR was significantly lower compared to healthy volunteers and during the entire study $[14,15]$. ASV indirectly acknowledges this hyperventilation by using algorithms with a target ventilation of only $90 \%$ of patients' minute ventilation analyzed over a period of the last $3 \mathrm{~min}$.

However, despite the built-in algorithm, our study even found a tendency for $\mathrm{PtcCO}_{2}$ to (further) decrease 
in both awake HF patients with CSR and awake healthy volunteers during $1 \mathrm{~h}$ of ASV and as compared to baseline.

There are two mechanisms that could help to understand why ASV was associated with a trend towards hyperventilation in both subject groups while awake during ASV. Firstly, it is generally accepted that positive airway pressure (PAP) devices can lead to hyperinflation (i.e. higher functional residual capacity) of the lungs through PAP [16]. An increase in dead space could have resulted in dyspnea, which in turn causes deeper breaths and increases in IPAP because dyspnea might be misinterpreted as an apnea. Secondly, in healthy volunteers naïve to PAP therapy, ASV might further exaggerate ventilation (induce ventilation instability), leading to false high presettings of the PaceWave ${ }^{\mathrm{TM}}$ device with inappropriately high target ventilation. The device would then even 'defend' its target minute ventilation against the subject's drive to breathe less by increasing PS. This would provide further explanation for the observed inappropriate increase in PS in rather hyperventilated (and awake) volunteers during ASV.

In contrast to wakefulness, we observed an appreciable increase in $\mathrm{PtcCO}_{2}$ and attenuation of hyperventilation during sleep in both HF patients and volunteers when on ASV and compared to $\mathrm{PtcCO}_{2}$ levels at baseline. More specifically, time spent sleeping during ASV even correlated with the change in $\mathrm{PtcCO}_{2}$, highlighting that increases in $\mathrm{PtcCO}_{2}$ were even more significant the more the subjects slept during ASV. Apparently, the ASV device used in this study probably succeeded at running its algorithm in sleeping subjects, which is in accordance with a previous work [9].

The different results found for $\mathrm{pCO}_{2}$ levels in dependency on vigilance during ASV are probably due to ventilatory control being largely dependent on consciousness [17-22]. During sleep, the control of breathing becomes dependent on chemical and mechanical reflex feedback $[17,22]$. The reason for this is loss of the so-called 'wakefulness drive', making it easier for any ventilation to change $\mathrm{CO}_{2}$ levels in men from early non-REM sleep stages onwards [17-19, 22].

The fact that CSR is accompanied by its characteristic hyperventilation (decrease in $\mathrm{pCO}_{2}$ ) from early sleep stages onwards makes it even more likely that the increase in $\mathrm{pCO}_{2}$ observed in our sleeping HF patients who are predisposed to CSR during sleep is a result of the treatment of hyperventilation by the built-in algorithm of the ASV device to treat hyperventilation $[23,24]$. The relevance of such algorithms favorably altering $\mathrm{pCO}_{2}$ in patients with CSR is well-underlined by studies demonstrat- ing that even slight increases in $\mathrm{pCO}_{2}$ of about $2 \mathrm{~mm} \mathrm{Hg}$ are sufficient to diminish CSR in HF patients $[4,15]$.

In contrast to patients with CSR, sensitivity towards $\mathrm{pCO}_{2}$ and breathing volume decrease during sleep in healthy men, resulting in increases in $\mathrm{pCO}_{2}$ from early non-REM sleep stages onwards $[20,21]$. Thus, the increase in $\mathrm{pCO}_{2}$ in volunteers during sleep and with ASV might be partly explained by physiological increases in $\mathrm{pCO}_{2}$ in sleeping healthy men and not necessarily by the ASV algorithm [20, 21].

This study has a number of limitations. Firstly, we were not able to analyze $\mathrm{pCO}_{2}$ invasively because the study was conducted in a sleep laboratory. However, the validity of transcutaneous blood gas analysis-derived $\mathrm{pCO}_{2}$ values has been widely confirmed $[25,26]$. Another limitation is the small sample size, which did not allow appropriate multivariate analyses. Despite this, statistically significant differences were found, and reasonable explanations for such differences have been provided.

In addition, any conclusions about the built-in 'Auto EPAP' function in the ASV device used in this study, should be drawn cautiously because it was not really utilized (table 1). In patients, the slight increase in EPAP seen during $1 \mathrm{~h}$ of ASV can probably be explained best by comorbid obstructive apneas requiring EPAP. In volunteers, the marginal increase in EPAP most likely occurred because all volunteers were naïve to any type of PAP device. Some of them may have marginally stopped breathing for a short period, which could have been misinterpreted by the device as an obstructive event necessitating EPAP. Finally, the ASV device software (ResScan Software) did not allow us to analyze respiratory parameters in different periods of ventilation, which is why we compared overall sleep and overall respiratory parameters during the $1 \mathrm{~h}$ of ASV.

In conclusion, this study shows that ASV treatment was associated with an increase in ventilation in awake HF patients with CSR and in awake healthy volunteers. In contrast, the desired normalization of respiration (attenuation of hyperventilation as one of the key pathophysiological principles of CSR) with ASV occurred during sleep.

\section{Acknowledgements}

English language editing assistance was provided by Nicola Ryan, independent medical writer, and funded by ResMed.

\section{Disclosure Statement}

The authors declare that they have no conflict of interest. 


\section{References}

1 Oldenburg O, Lamp B, Faber L, Teschler H, Horstkotte D, Töpfer V: Sleep-disordered breathing in patients with symptomatic heart failure: a contemporary study of prevalence in and characteristics of 700 patients. Eur J Heart Fail 2007;9:251-257.

2 Gottlieb DJ: The Sleep Heart Health Study: a progress report. Curr Opin Pulm Med 2008; 6:537-542.

-3 Oldenburg O: Cheyne-Stokes respiration in chronic heart failure - treatment with adaptive servoventilation therapy. Circ J 2012;76: 2305-2317.

4 Lorenzi-Filho G, Rankin F, Bies I, Douglas Bradley T: Effects of inhaled carbon dioxide and oxygen on Cheyne-Stokes respiration in patients with heart failure. Am J Respir Crit Care Med 1999;159:1490-1498.

5 Naughton MMT: Cheyne-Stokes respiration: friend or foe? Thorax 2012;67:357-360.

-6 Oldenburg O, Spießhöfer J, Fox H, Bitter T, Horstkotte D: Cheyne Stokes respiration in heart failure: friend or foe? Hemodynamic effects of hyperventilation in heart failure patients and healthy volunteers. Clin Res Cardiol 2014, Epub ahead of print.

-7 Cowie MR, Woehrle H, Wegscheider K, Angermann C, d'Ortho MP, Erdmann E, Levy P, Simonds A, Somers VK, Zannad F, Teschler $\mathrm{H}$ : Rationale and design of the SERVE-HF study: treatment of sleep-disordered breathing with predominant central sleep apnoea with adaptive servo-ventilation in patients with chronic heart failure. Eur J Heart Fail 2013;15:937-943.

8 Fietze I, Blau A, Glos M, Theres H, Baumann G, Penzel T: Bi-level positive pressure ventilation and adaptive servo ventilation in patients with heart failure and Cheyne-Stokes respiration. Sleep Med 2008;9:652-659.
9 Teschler H, Döhring J, Wang YM, BerthonJones M: Adaptive pressure support servoventilation: a novel treatment for CheyneStokes respiration in heart failure Am J Respir Crit Care Med 2001;164:614-619.

10 D'Elia E, Vanoli E, La Rovere MT, Fanfulla F, Maggioni A, Casali V, Damiano S, Specchia G, Mortara A: Adaptive servo ventilation reduces central sleep apnea in chronic heart failure patients: beneficial effects on autonomic modulation of heart rate. J Cardiovasc Med 2013;4:296-300.

11 Oldenburg O, Spießhöfer J, Fox H, Prib N, Horstkotte D: Performance of conventional and enhanced adaptive servoventilation (ASV) in heart failure patients with central sleep apnea who have adapted to conventional ASV. Sleep Breath 2014, Epub ahead of print.

12 Oldenburg O, Bitter T, Lehmann R, Korte S, Dimitriadis Z, Faber L, Schmidt A, Westerheide N, Horstkotte D: Adaptive servoventilation improves cardiac function and respiratory stability. Clin Res Cardiol 2011;2:107115.

13 Berry RB, Budhiraja R, Gottlieb DJ, Gozal D, Iber C, Kapur VK, Marcus CL, Mehra R, Parthasarathy S, Quan SF, Redline S, Strohl KP, Davidson Ward SL, Tangredi MM: Rules for scoring respiratory events in sleep: update of the 2007 AASM Manual for the Scoring of Sleep and Associated Events Deliberations of the Sleep Apnea Definitions Task Force of the American Academy of Sleep Medicine. J Clin Sleep Med 2012;8:597-619.

14 Bitter T, Westerheide N, Hossain SM, Prinz C, Horstkotte D, Oldenburg O: Symptoms of sleep apnoea in chronic heart failure - results from a prospective cohort study in 1,500 patients. Sleep Breath 2012;3:781-791.

15 Xie A, Rankin F, Rutherford R, Bradley TD Effects of inhaled $\mathrm{CO}_{2}$ and added dead space on idiopathic central sleep apnea. J Appl Physiol 1997;3:918-926.
16 Braga CW, Chen Q, Burschtin OE, Rapoport DM, Ayappa I: Changes in lung volume and upper airway using MRI during application of nasal expiratory positive airway pressure in patients with sleep-disordered breathing. J Appl Physiol 2011;5:1400-1409.

17 Skatrud JB, Dempsey JA: Interaction of sleep state and chemical stimuli in sustaining rhythmic ventilation. J Appl Physiol 1983;3: 813-822.

18 Dempsey JA: Crossing the apnoeic threshold: causes and consequences. Exp Physiol 2005; 1: 13-24.

19 Orem J, Osorio I, Brooks E, Dick T: Activity of respiratory neurons during NREM sleep. J Neurophysiol 1985;5:1144-1156.

20 Schäfer T: Variability of vigilance and ventilation: studies on the control of respiration during sleep. Respir Physiol 1998;114:37-48.

21 Krieger J, Maglasiu N, Sforza E, Kurtz D: Breathing during sleep in normal middleaged subjects. Sleep 1990;13:143-154.

22 Skatrud JB, Berssenbrugge AD: Effect of sleep state and chemical stimuli on breathing. Prog Clin Biol Res 1983;136:87-95.

23 Naughton M, Benard D, Tam A, Rutherford $\mathrm{R}$, Bradley TD: Role of hyperventilation in the pathogenesis of central sleep apneas in patients with CHF. Am Rev Respir Dis 1993;148: 330-338.

24 Hanly P, Zuberi N, Gray R: Pathogenesis of Cheyne-Stokes respiration in patients with congestive heart failure: relationship to arterial $\mathrm{PCO}_{2}$. Chest 1993;104:1079-84.

25 Storre JH, Steurer B, Kabitz HJ, Dreher M, Windisch W: Transcutaneous $\mathrm{PCO}_{2}$ monitoring during initiation of noninvasive ventilation. Chest 2007;132:1810-1816.

26 Schäfer T: Method for measuring respiration in sleep: capnography for determining ventilation. Biomed Tech 2003;48:170-175. 